\title{
Teaching and Learning German as a Foreign Language: Two Competing Perspectives?
}

\author{
Britta Schneider (Monash)
}

Over the years, increasing knowledge of the processes involved in second and foreign language learning has led to teaching methods that are less one-dimensional and less rigorous in their claims of absoluteness and general validity. Modern approaches to second language acquisition and foreign language teaching research acknowledge the fact that learners follow their own path of development and that their degree of access to natural, authentic input in the target language leads to different levels of proficiency and learning outcomes (cf. Boss and Diehl, this volume). Although the role of grammar teaching has changed significantly over the past four decades, it has experienced a revival in second and foreign language acquisition research and in today's foreign language classes it has reconquered much of the teaching time. However, as foreign language teachers we are all very aware that students want to learn the real language that native speakers use rather than isolated grammatical sequences of the target language.

On the basis of data collected for the purpose of a research project that investigated contextual factors affecting the delivery of foreign language teaching in higher education in Australia, I began researching connections between students' perceptions of language learning and the existing teaching syllabus. This led to the discovery of a number of discrepancies between the two perspectives, on some of which this article will report. While the research project is based on a large amount of data collected during three years (2001-2003), the following discussion presents only a subset of the responses to a survey among students of intermediate and advanced German as a Foreign Language (GFL) tutorials at Monash University. The survey was carried out in a four-week period in 2002 and questionnaires were administered to a total of 106 students with a return rate of 47.6 per cent. The questionnaire was returned by 29 students who were enrolled in intermediate GFL tutorials $(n 1=29)$ and 21 advanced GFL students $(\mathrm{n} 2=21)$. The survey covered five areas, such as learner 
demographics, (foreign) language learning backgrounds, self-perceived proficiency levels, the use of language learning strategies, attitudes towards classroom language learning, and the students' motives for studying a foreign language at university.

This article will focus on the following areas: firstly, the students' tutored and untutored foreign language contacts and their reasons for studying German at tertiary level will be analysed in order to identify the characteristics of the student body enrolled in tertiary GFL courses. Secondly, the quality and quantity of German language practice opportunities used by students outside the classroom will be investigated with regard to two selected language skills. This will help to identify teaching areas that need to be improved in terms of learner autonomy and learner centredness. Thirdly, the students' self-perceived proficiency levels will be analysed in terms of their self-awareness of strengths and weaknesses in their language acquisition process. Since language curriculum development often starts with determining how teaching can address the specific needs of learners, learners are considered as being the best judges of their own needs.

The questionnaire asked students to state their mother tongue (L1) and describe their untutored and tutored contact with languages other than English (LOTE). Preliminary investigations of tertiary students learning German (Schneider 2004: 144-145) had revealed a remarkable diversity of L1 backgrounds and considerable tutored L2 learning experiences during primary and secondary school. Tables 1 and 2 reveal the number of students within the two researched cohorts who have a LOTE background.

Table 1: LOTE background (Intermediate GFL Learners)

\begin{tabular}{cc}
\hline LOTE background & German background \\
\hline $11(37.9 \%)$ & $4(13.8 \%)$ \\
\hline$n 1=29$ &
\end{tabular}


Table 2: LOTE background (Advanced GFL Learners)

\begin{tabular}{lc}
\hline LOTE background & German background \\
\hline $5(23.8 \%)$ & $2(9.5 \%)$ \\
$n 2=21$ & \\
\end{tabular}

Approximately one third of the respondents in each cohort report a LOTE background and the largest group among them reveal a Germanspeaking ancestry. According to the 2001 Australian Census, the proportion of the Australian population with German-speaking ancestry was 4.3 per cent. A comparison of the Census figures with the data above confirms what Ammon (1991) found in his study of Australian university students of German: the percentage of students with a German-speaking family background who enrol in GFL studies is proportionally higher than the percentage of ethnic German speakers in the Australian population (Ammon 1991: 73-74).

With regard to the respondents' foreign language learning (FLL) experiences in school, the average number of years and the diversity of foreign languages studied is quite high, as Tables 3 and 4 illustrate.

Table 3: School-based FLL and Length of Study (Intermediate GFL Learners)

\begin{tabular}{lrrr}
\hline Foreign language & Respondents & In \% & Average Years of Study \\
\hline German & 19 & 65.5 & 4.6 \\
French & 10 & 34.5 & 2.9 \\
Japanese & 6 & 20.7 & 2.4 \\
English (ESL) & 5 & 17.5 & 7.2 \\
Indonesian & 3 & 10.3 & 4.5 \\
Italian & 2 & 6.9 & 2 \\
Russian & 1 & 3.4 & 4 \\
Chinese & 1 & 3.4 & 0.6 \\
Maori & 1 & 3.4 & 0.6 \\
\hline
\end{tabular}

$\mathrm{n} 1=29$ 
Table 4: School-based FLL and Length of Study (Advanced GFL Learners)

\begin{tabular}{lrrr}
\hline Foreign language & Respondents & In \% & Average Years of Study \\
\hline German & 21 & 100 & 6.45 \\
Japanese & 7 & 33.3 & 2.9 \\
French & 4 & 19.0 & 2.5 \\
English (ESL) & 3 & 14.3 & 8.3 \\
Indonesian & 3 & 14.3 & 2.2 \\
Chinese & 3 & 14.3 & 3 \\
Italian & 2 & 9.5 & 7.5 \\
Indonesian & 1 & 4.8 & 1 \\
Maori & 1 & 4.8 & 1 \\
\hline n2 $=21$ & & &
\end{tabular}

The wide range of foreign languages learned at school is remarkable: students came into tutored contact with nine foreign languages, German, French and Japanese being the most commonly taught L2s. The number of students who studied German at school is also quite high with 65.5 per cent in the intermediate group and 100 per cent in the advanced group. It can be observed that despite having studied German for an average length of 4.6 years, students in the intermediate group chose to enrol in the introductory or intermediate stream of German at university.

A closer examination of motivational aspects of tertiary language learning unfolds a rather complex motivational structure among the respondents (see Table 5). The questionnaire aimed to determine the learners' long-term goal orientations and their motives for studying a foreign language at tertiary level, as well as to map areas of tertiary language teaching that students were the most interested in. ${ }^{1}$

\footnotetext{
${ }^{1}$ For an overview and explanation of terms and concepts used in L2 motivational research refer to Gardner 1985, Gardner \& MacIntyre 1993, Dörnyei 1998, and Dörnyei \& Ottó 1998. For a detailed description of the framework used in the present study to analyse and interpret students' motivational structure refer to Schneider 2004: 274-280.
} 
Table 5: Motives for Learning a Foreign Language at University

\begin{tabular}{lrrrr}
\hline \multicolumn{1}{c}{ Motives } & \multicolumn{2}{r}{ Intermediate GFL Learners } & \multicolumn{2}{r}{ Advanced GFL Learners } \\
& & 13.8 & 5 & 23.8 \\
\hline For study reasons & 4 & 31.0 & 8 & 38.1 \\
For occupational reasons & 9 & 10.3 & 5 & 23.8 \\
For cultural reasons & 3 & 51.7 & 12 & 57.1 \\
For personal reasons & 15 & - & - & - \\
Others & - & - & 1 & 4.8 \\
na & - & &
\end{tabular}

Response Rates: $\mathrm{n} 1=29(100 \%) ; \mathrm{n} 2=21(95.2 \%)$

The data above reveal that there is no single strong motive. Although asked to select only one of the options almost all respondents selected two or more which reflects their complex motivational structure. A slight majority stated personal reasons as the main motive for studying a foreign language. Personal reasons include aspects such as having a family or friends in or of the target language community, the wish to travel overseas or some kind of vague personal interest. The second most widely chosen motive was for occupational reasons, which include the wish to work abroad or in companies associated with the target country. Cultural reasons ranked third and were selected by students who wished to learn the language in order to be culturally better informed when visiting the target country or because of an interest in cultural studies. Last on the list of learner motives were study reasons, a category that contains aspects such as the wish to go abroad and study at a German-speaking university, to pursue postgraduate studies, or to become a foreign language teacher. In summary, non-academic long-term orientations provide the first impetus for initiating tertiary foreign language studies.

In order to find out more about the academic versus vocational orientation of the students, the questionnaire asked them to rank nine potential areas of tertiary GFL studies according to their degree of interest. The following table shows the frequency with which respondents ranked those areas first, second and third most important. 
Table 6: GFL Subject Areas of Interest

\begin{tabular}{lrrrr}
\multicolumn{1}{c}{ Study Areas } & $\begin{array}{c}\text { Intermediate GFL } \\
\text { Learners }\end{array}$ & \multicolumn{3}{c}{$\begin{array}{c}\text { Advanced GFL } \\
\text { Learners }\end{array}$} \\
\hline Learning the language & 28 & 96.5 & 20 & 95.2 \\
L2 Literature & 4 & 13.8 & 2 & 9.5 \\
L2 Linguistics & 11 & 37.9 & 5 & 23.8 \\
Second language acquisition & 18 & 62.1 & 15 & 71.4 \\
L2 History & 11 & 37.9 & 5 & 23.8 \\
L2 Contemporary issues & 4 & 13.8 & 3 & 14.3 \\
L2 Culture & 8 & 27.6 & 9 & 42.9 \\
L2 Business Language & 4 & 13.8 & 3 & 14.3 \\
L2 philosophy & 4 & 13.8 & 1 & 4.8 \\
Other & 4 & - & - & - \\
(Speaking/Communication) & $(3)$ & & & \\
(Grammar) & $(1)$ & & & \\
na & 1 & 3.4 & 0.5 & 2.4 \\
\hline
\end{tabular}

Response Rates: $\mathrm{n} 1=29(96.5 \%) ; \mathrm{n} 2=21(97.6 \%)$

Intermediate German learners reported that they were primarily interested in attending the language tutorials, linguistics lectures, and lectures on second language acquisition when available. Culture and history related subject components were ranked next. The data suggest that the interviewees have a pragmatic orientation towards their tertiary language studies. They clearly articulate their need to first gain an understanding of the linguistic properties of the target language before engaging with culture and literature related areas of their studies. This observation fits in with the claim made earlier that although rich in school-based GFL learning experiences, students do not feel ready to enrol in the advanced stream at university.

Advanced German learners demonstrate the same priority for first learning formal properties of the L2, but they show an increased interest in culture related subject components. 
The study also sought to explore students' learning activities outside class in order to determine the extent to which they engage in language learning beyond the immediate classroom context. Learners were expected to be particularly active in creating practice opportunities outside class in areas which they identified as most important to their acquisition process. Due to the wealth of data obtained in response to the relevant questions, this section only presents selected data regarding practice opportunities for grammar and speaking. The former was the focus of the existing teaching syllabus, whereas the latter was selected by a majority of students as the most important skill to acquire at university. Table 7 reflects the students' learning priorities and Table 8 presents language skills that were most often assessed and therefore in focus in the teaching syllabus.

Table 7: Most Important Skills in Tertiary Studies (Learner Perspective)

\begin{tabular}{ll} 
Intermediate GFL Learners & \multicolumn{1}{c}{ Advanced GFL Learners } \\
\hline Speaking & Speaking \\
Listening Comprehension & Listening Comprehension \\
Vocabulary & Writing \\
Reading & Vocabulary \\
Grammar & Grammar \\
& Reading \\
Writing & Learning Strategies; \\
& Culture \\
Learning Strategies & \\
Culture & \\
\hline
\end{tabular}


Table 8: Assessment Tasks of Intermediate and Advanced GFL Tutorials

\begin{tabular}{lrr}
\hline \multicolumn{1}{c}{ Tasks } & $\begin{array}{c}\text { Intermediate } \\
\text { GFL } \\
\text { Weight in \% }\end{array}$ & $\begin{array}{c}\text { Advanced } \\
\text { GFL } \\
\text { Weight in \% }\end{array}$ \\
\hline Fortnightly grammar homework & 12.5 & 10.0 \\
Fortnightly grammar /vocabulary test & 12.5 & 10.0 \\
1 Essay & 7.5 & 10.0 \\
1 Composition Test & 7.5 & 16.0 \\
1 Listening Comprehension Test & 5.0 & 6.0 \\
Written Test 1 (mid-semester grammar test) & 15.0 & 16.0 \\
Written Test 2 (end-semester grammar test) & 20.0 & 16.0 \\
1 Oral test (end of semester) & 20.0 & 16.0 \\
\hline
\end{tabular}

From the learners' point of view, learning how to speak German, together with being able to understand native German speakers and building a rich lexicon are perceived as priorities. In contrast, Table 8 demonstrates that the testing of grammar accounts for 50 to 60 per cent of the overall assessment, which implies that most of the actual class time is spent on teaching and testing grammar. A thorough analysis of learners' spoken and written L2 productions, which would go beyond the scope of this article, further showed that most learners could not comply with the demands of the existing teaching syllabus to consciously process and actively use taught target structures (cf. Schneider 2004: 162-208).

Whilst learner and teacher perceptions of the most important skills to learn in tertiary foreign language learning disagree, the students' means and efforts to create learning opportunities outside class naturally reflect the existing teaching syllabus and its focus on grammar (cf. Table 9). 
Table 9: Speaking Practice Opportunities Outside Class

\begin{tabular}{lrrrr}
\hline \multicolumn{1}{c}{ Activity } & $\begin{array}{c}\text { Intermediate GFL } \\
\text { Learners }\end{array}$ & \multicolumn{2}{c}{$\begin{array}{c}\text { Advanced GFL } \\
\text { learners }\end{array}$} \\
& & $\%$ & & $\%$ \\
\hline Speaking to native speakers & 10 & 34.5 & 16 & 76.2 \\
Calling friends/family in L2 country & 2 & 6.9 & 7 & 33.3 \\
Inventing dialogues with fellow & 5 & 17.2 & 2 & 9.5 \\
students & & & & \\
Speech exercises in textbook & 11 & 37.9 & 4 & 19.0 \\
Others & 3 & 10.3 & - & - \\
Nothing & 8 & 27.6 & 4 & 19.0 \\
Total of Responses & & & & \\
\hline
\end{tabular}

Response Rates: $100 \%, \mathrm{n} 1=29 ; 100 \%, \mathrm{n} 2=21$

The number of students who report practising with native speakers outside class is quite high, especially among the advanced learners. This stands in contrast with the small number of students who indicated having a German-speaking family background (cf. tables 1 and 2). Although students want to learn to speak the target language, they are very restricted in the ways they create opportunities for speaking practice outside class. Most of the few activities mentioned are initiated by the teacher and the textbook used in class. Only a small proportion of students mention strategies which are independent of the classroom, such as practising their oral skills with fellow students by inventing dialogues.

Table 10: Grammar practice opportunities outside class

\begin{tabular}{lcrrr}
\hline \multicolumn{1}{c}{ Activity } & $\begin{array}{c}\text { Intermediate GFL } \\
\text { Learners }\end{array}$ & \multicolumn{2}{c}{$\begin{array}{c}\text { Advanced GFL } \\
\text { Learners }\end{array}$} \\
\hline Studying rules in book & 22 & 75.9 & 17 & 81.0 \\
Doing book exercises & 25 & 86.2 & 16 & 71.4 \\
Doing other exercises & 12 & 41.8 & 12 & 57.1 \\
Studying with fellow student & 6 & 20.7 & 1 & 4.8
\end{tabular}




\begin{tabular}{lrrrr} 
Listening/Learning whole sentences & 22 & 75.9 & 14 & 66.7 \\
Using Internet websites & 3 & 10.3 & 3 & 14.3 \\
$\begin{array}{l}\text { Don't particularly 'love' grammar, } \\
\text { therefore learn it by ear }\end{array}$ & 12 & 41.8 & 5 & 23.8 \\
$\begin{array}{l}\text { Others } \\
\text { Nothing }\end{array}$ & 1 & 3.4 & 1 & 4.8 \\
Total of Responses & $\mathbf{1 0 3}$ & - & - & - \\
\hline
\end{tabular}

Response Rates: $100 \%, \mathrm{n} 1=29 ; 100 \%, \mathrm{n} 2=21$

Table 10 presents the activities undertaken to study grammar outside class and all students indicated drawing primarily on classroom material, such as textbook and workbook exercises. Interestingly, a high number of intermediate students state that they learn grammar by listening to or learning whole sentences which reflects a learning style that Skehan (1998: 250) referred to as "high memory" learning. These learners try to memorise whole sentences as partly unanalysed samples of the target language. They do so because they do not particularly enjoy learning grammar and would therefore rather learn structures by ear than consciously learning and analysing the rules.

The use of grammar internet sites is very low which suggests that learners either do not feel encouraged by their teachers to use them or that they do not have the appropriate skills to independently search for suitable web-based grammar material. The impression that students invest far more time in consciously studying grammar rules and structures is further reinforced by the following two tables which illustrate the amount of time invested in these learning activities outside the classroom.

Table 11: Frequency Rate of Speaking Activities Outside Class

\begin{tabular}{lrrrr}
\hline \multicolumn{1}{r}{ Frequency } & Intermediate GFL Learners & \multicolumn{2}{r}{ Advanced GFL Learners } \\
& \multicolumn{1}{c}{$\%$} & 12.8 & 2 & $\% .1$ \\
\hline Daily & 5 & - & - & - \\
3-4 Times a Week & - & - & - & - \\
2-3 Times a Week & - & 46.2 & 16 & 48.5 \\
Once a Week & 18 & - & 1 & 3.0 \\
\hline
\end{tabular}




\begin{tabular}{llllr}
\hline Occasionally & 4 & 10.3 & 8 & 24.2 \\
Never & 8 & 20.5 & 4 & 12.1 \\
$\mathrm{Na}$ & 4 & 10.3 & 2 & 6.1 \\
\hline
\end{tabular}

Total of nominations $\mathrm{nA}=39$ (for $\mathrm{n} 1$ ); $\mathrm{nB}=33$ (for $\mathrm{n} 2$ )

Table 12: Frequency Rate of Grammar Activities Outside Class

\begin{tabular}{lrrrr}
\hline \multicolumn{1}{r}{ Frequency } & \multicolumn{2}{r}{ Intermediate GFL Learners } & Advanced GFL Learners \\
& & $\%$ & $\%$ \\
\hline Daily & 18 & 17.5 & 7 & 10.1 \\
3-4 Times a week & 5 & 4.9 & - & - \\
2-3 Times a week & 4 & 3.9 & 2 & 2.9 \\
Once a week & 73 & 70.9 & 52 & 75.4 \\
Once a Month & - & - & 1 & 1.4 \\
Occasionally & 2 & 1.9 & 6 & 8.7 \\
na & 1 & 1.0 & 1 & 1.4 \\
\hline
\end{tabular}

$\mathrm{nA}=103 ; \mathrm{nB}=69$

A comparison of the frequency of practice opportunities for grammar and for speaking shows that students put a lot more effort into the learning and understanding of grammar than they do for speaking. Among the learners 70 to 75 per cent state that they engage at least once a week in some sort of grammar exercise outside class. Not even half the cohorts indicate that they practise speaking the target language once a week. This learner behaviour does not only reflect the grammar-driven teaching plan, but also suggests that the students do not know how to best train the different language skills independently. Everyone who has invested some time in foreign language learning must admit that practising outside class once a week is not sufficient and cannot be regarded as a sustained learning effort.

This section discusses the question of whether students' ability to selfevaluate their German language skills is accurate or not. By comparing the students' self-ratings to their assessment grades, the study wanted to further establish whether learner and teacher perceptions of learning and 
teaching a foreign language match. This comparison also refers to the previously discussed topic of learner practice opportunities outside class and seeks to answer the question of whether students' efforts and time invested in grammar learning outside class leads to the desired learning outcome in terms of assessment results. Tables 13 and 14 show how often students' own assessments agree or disagree with that of their teachers and whether the learners under- or overestimate their proficiency levels.

Table 13: Assessment and Self-Ranking (Intermediate GFL Learners)

\begin{tabular}{lrrrrr}
\hline Language Skill & Agreement & $\begin{array}{c}\text { Higher Self- } \\
\text { Ranking }\end{array}$ & $\begin{array}{c}\text { Lower Self- } \\
\text { Ranking }\end{array}$ & $\begin{array}{c}\text { No Comparison } \\
\text { Possible }\end{array}$ \\
\hline Speaking & 6 & 8 & 13 & 2 \\
Listening & 9 & 5 & 12 & 3 \\
Writing & 6 & 13 & 8 & \\
Grammar & 10 & 12 & 5 & 2 \\
\hline
\end{tabular}

$\mathrm{n} 1=29$

Table 14: Assessment and Self-Ranking (Advanced GFL Learners)

\begin{tabular}{lrrrrr}
\hline Language Skill & Agreement & $\begin{array}{c}\text { Higher Self- } \\
\text { Ranking }\end{array}$ & $\begin{array}{c}\text { Lower Self- } \\
\text { Ranking }\end{array}$ & $\begin{array}{c}\text { No Comparison } \\
\text { Possible }\end{array}$ \\
\hline Speaking & 4 & 8 & 9 & 0 \\
Listening & 6 & 2 & 13 & 0 \\
Writing & 6 & 6 & 9 & 0 \\
Grammar & 7 & 14 & 0 & 0 \\
\hline
\end{tabular}

$\mathrm{n} 2=21$

The data above demonstrate that in all areas but grammar the majority of learners tend to rank their self-perceived proficiency level lower than their actual achievement in the assessment tasks. However, the data also reveal that students' perception of their grammar skills match the teachers' assessment more often than in any other language area. Whereas a majority of students perceive their grammar competence as good, the assessment reflects a lower evaluation of their actual performance. The 
learners' self-appraisal concerning their grammar skills suggests that they feel in control. This can be explained by the nature of 'grammar' per se with its closed categories, which is something learners can (or think they can) control even if they do not.

Language learning in a tutored environment is a highly complex process influenced by a variety of factors. The discussion of the data presented in this paper points out areas of tertiary foreign language teaching that need to be revisited in order to reconcile learner and teacher perspectives on the acquisition of a foreign language. Thus the introduction of a language learning portfolio ${ }^{2}$ would present both learners and teachers with an excellent tool for a more balanced learning and teaching process for the following reasons:

1. The data on the students' language learning experiences illustrated the extremely rich foreign language learning background of tertiary students, as well as the diversity of first languages present in the classroom. Teachers should be encouraged to guide students in meaningful ways to use their existing (foreign) language knowledge when studying German. A language learning portfolio would help learners to track their strengths and weaknesses in the language acquisition process. The data also demonstrate that for Australian learners of German as a foreign language ancestry and family background play a vital role in a student's initial decision to take on German at university. Teachers could use this knowledge in order to make the learning experience more personal for the individual learner.

2. The brief investigation of motivational aspects illustrated that students decide to study. German at university for a number of reasons, but firstly because of some personal interest and/or family background and secondly because German is perceived as a language that will help them in their future professional career. Students still regard German as a language that will improve their chances on the labour market. University teaching should therefore strengthen existing

\footnotetext{
${ }^{2}$ In analogy to the "European Language Portfolio" (1996).
} 
motives in order to increase learners' goal directedness and motivation.

3. The data on students' learning habits outside class for the language skills speaking and grammar revealed that practice methods outside class correlate with the requirements of the teaching syllabus as opposed to the students' own requirements. Students identified speaking as the most important skill to learn at university, and yet most of their learning time and effort inside and outside class was spent on grammar. The obvious dependence on teachers and classroom activities for engaging in learning activities outside class demonstrates that students do not recognise or feel encouraged to learn proactively outside class. A language learning portfolio would increase learners' influence on the content and degree of their learning activities and would also encourage them to take over ownership of their learning process.

4. Learner activities outside class are not frequent enough to ensure "sustained deep learning" (cf. Schneider 2004:151-153). The quality and frequency of practice opportunities indicate that current classroom teaching does not sufficiently encourage independent language learning activities. The unsustained nature of practice activities outside class signals a lack of responsibility for the acquisition process. It would seem that teachers are required to give more incentives in order to encourage learners to actively seek and create practice opportunities for themselves. Therefore learners' efforts outside class need to be increasingly integrated into the existing teaching and assessment.

5. A comparison of learners' self-perceived proficiency levels and corresponding assessment marks suggests that the assessment tasks used are not suitable to assess proficiency levels objectively. Assessment tasks combining learner work and self-reflective assessment would incorporate both a pedagogic and reporting function.

Although the data presented are part of a study that focuses explicitly on the Australian university system and the language programme at one 
particular university, the fundamental questions about teaching German as a Foreign Language in the tertiary context can be transferred to the international context. This includes questions regarding teachers' knowledge about processes in the learning and teaching of a foreign language and their application to classroom interaction and curriculum development, as well as the fundamental role of teacher training and professional development. This paper concludes by stressing the continuing unequal distribution between grammatical instruction and training in practical language abilities, that is communicative competence, in tertiary German language curricula. It highlights only a few of the measures which would allow closing the gap between the perspectives of students and teachers in order to optimise language acquisition and language knowledge in tertiary education. 